\title{
Sudden Cardiac Death in a Patient with Systemic Lupus Erythematosus and Cytomegalovirus Myocarditis
}

Justin Chow, MD, FRCPC ${ }^{1,2}$, Umair Iftikhar, MD ${ }^{1,3}$, Victoria Weaver, MD, FRCPC ${ }^{1,4}$, Kwadwo Mponponsuo, MD ${ }^{1,5}$, Amy Bromley, MD, FRCPC ${ }^{6}$

${ }^{1}$ Department of Medicine, University of Calgary, Calgary, AB, Canada;

${ }^{2}$ Department of Medicine, Division of Cardiology, McMaster University, Hamilton, ON, Canada;

${ }^{3}$ Department of Medicine, Division of Cardiology, McGill University, Montreal, QC, Canada;

${ }^{4}$ Department of Medicine, Division of Infectious Diseases, University of British Columbia, Vancouver, BC, Canada;

${ }^{5}$ Department of Medicine, Division of Infectious Diseases, University of Calgary, Calgary, AB, Canada;

${ }^{6}$ Department of Pathology and Laboratory Medicine, University of Calgary, Calgary, AB, Canada

Corresponding Author: Dr. Justin Chow: justin.chow@medportal.ca

Submitted: October10, 2019; Accepted: November 16, 2019; Published: 18 November, 2020.

DOI: http://dx.doi.org/10.22374/cjgim.v15i4.400

\section{Abstract \\ Background}

Myocarditis is generally a self-limited illness with a benign course. Certain pathogens-such as cytomegalovirus (CMV) - can cause severe/fulminant forms of myocarditis leading to congestive heart failure or sudden cardiac death (SCD).

\section{Case Presentation}

A 54-year-old female was diagnosed with systemic lupus erythematosus (SLE) in hospital and received inpatient immunosuppression due to significant multi-organ involvement. After a prolonged admission, she later died of an in-hospital cardiac arrest. Autopsy revealed CMV myocarditis involving the anterior wall of the left ventricle and cardiac conduction system. We postulated that both CMV and complications of SLE caused the patient's SCD.

\section{Discussion}

Myocarditis can vary in its presentation, severity, and diagnostic workup. Immunocompromised hosts are at risk of opportunistic infections such as CMV and are therefore prone to developing more severe forms of myocarditis. When caring for this patient population, it becomes necessary for clinicians to consider atypical manifestations of opportunistic pathogens in their diagnostic approach.

\section{RESUME}

\section{Contexte}

La myocardite est généralement une maladie autolimitée dont l'évolution est bénigne. Certains agents pathogènes, tels que le cytomégalovirus (CMV), peuvent provoquer des formes graves/ fulminantes de myocardite entraînant une insuffisance cardiaque congestive ou une mort cardiaque subite (MCS). 


\section{Présentation de cas}

Une femme de 54 ans a reçu un diagnostic de lupus érythémateux disséminé (LED) à l'hôpital et a été hospitalisée pour une immunosuppression due à une importante atteinte de plusieurs organes. Après une longue hospitalisation, elle est décédée d'un arrêt cardiaque à l'hôpital. L'autopsie a révélé une myocardite à CMV impliquant la paroi antérieure du ventricule gauche et le système de conduction cardiaque. Nous avons émis l'hypothèse que le CMV et les complications du LED étaient tous deux à l’origine de l'arrêt cardiaque de la patiente.

\section{Discussion}

La myocardite peut varier dans sa présentation, sa gravité et son diagnostic. Les hôtes immunodéprimés sont exposés au risque d'infections opportunistes telles que le CMV et sont donc susceptibles de développer des formes plus graves de myocardite. Lorsqu'ils soccupent de cette population de patients, les cliniciens doivent tenir compte des manifestations atypiques des agents pathogènes opportunistes dans leur approche diagnostique.

Keywords: cytomegalovirus; myocarditis; sudden cardiac death; systemic lupus erythematosus

\section{Case Presentation}

A 54-year-old female presented to the emergency department with 4 weeks of fever, malaise, and anorexia. Her past medical history included osteoporosis as well as a history of inflammatory poly-arthralgia, not yet diagnosed-for which she was undergoing outpatient workup by a rheumatologist. Family history was significant for a sibling who had died in her forties from complications related to systemic lupus erythematosus (SLE). The patient's only medications were alendronate and analgesics (celecoxib and tramadol) as needed.

On examination, the patient's temperature was $38.1^{\circ} \mathrm{C}$, blood pressure $85 / 58 \mathrm{mmHg}$ with orthostatic changes, heart rate of 88 beats per minute, and respiratory rate of 18 breaths per minute. Oxygen saturation was $74 \%$ on room air and increased to $92 \%$ with $4 \mathrm{~L}$ of supplemental oxygen. Jugular venous pressure was flat and oral mucosa was dry in keeping with intravascular volume depletion. On auscultation, breath sounds were decreased with bibasilar crackles. On examination, no other localizing signs of infection were noted.

Admission investigations showed a white blood cell (WBC) count of 1.7 (normal 2.0-9.0) $\times 10^{9}$, mild elevation in high-sensitivity troponin $\mathrm{T}$ of 22 (normal $0-14$ ) ng/L, and mild liver function test abnormalities: alanine transaminase (ALT) 89 (normal 1-40) U/L, alkaline phosphatase (ALP) 108 (normal 30-115) U/L, gamma-glutamyltransferase (GGT) 113 (normal 8-35) U/L, and lipase 204 (normal 0-80) U/L. Other labs were normal. A 12-lead electrocardiogram showed normal sinus rhythm. A portable anterior-posterior chest x-ray in the emergency department revealed consolidation of the right lower lobe (Figure 1). The patient was subsequently admitted to the hospital with a diagnosis of sepsis due to community-acquired pneumonia.

The patient was started on intravenous (IV) fluids and antibiotics (ceftriaxone and azithromycin). Given the mild troponin elevation, a transthoracic echocardiogram was performed to assess cardiac dysfunction; this study was normal. Despite the initial clinical improvement, the patient developed severe acute respiratory distress syndrome requiring intubation and admission to the intensive care unit (ICU). Continuous renal replacement therapy was initiated to manage acute renal failure. An extensive infectious workup including bronchoalveolar lavage and lumbar puncture failed to yield a microbiologic diagnosis. Rheumatologic consultation was obtained given the patient's history of inflammatory polyarthralgia, family history of SLE, and leukopenia. She was ultimately diagnosed with SLE based on hypocomplementemia and a positive anti-ribosomal $\mathrm{P}$ antigen (of note, the antinuclear antibody was positive at 1:80 and antidouble-stranded DNA was negative). In addition to empiric broad-spectrum antibiotics, the patient underwent combined immunosuppressive therapy with IV steroids, immune globulin, and cyclophosphamide. These measures again resulted in clinical improvement and eventual transfer back to the ward.

Unfortunately, 10 days after leaving the ICU the patient suffered a witnessed cardiac arrest while ambulating to the washroom and a code blue was activated immediately. Her initial cardiac rhythm was a pulseless electrical activity which later degenerated to ventricular fibrillation. Despite exhaustive resuscitative efforts and the eventual return of spontaneous circulation, the patient developed refractory shock and multi-organ dysfunction. She died several hours later in the ICU. 


\section{Autopsy Findings}

An autopsy was requested to clarify the patient's terminal events and underlying diagnosis. At autopsy, she was found to have bilateral cytomegalovirus (CMV) pneumonitis (Figure 2). Cardiac examination revealed severe multi-vessel coronary artery disease, with a $90 \%$ stenosis of the left main coronary artery, $75 \%$ stenosis of the mid-left anterior descending coronary artery, and $50 \%$ stenosis of the mid-right coronary artery. Despite this, no evidence of myocardial infarction, fibrosis, or ischemia was identified.

Interestingly, a single definitive focus of myocarditis was identified in the anterior wall of the left ventricle with destructive neutrophilic inflammation and CMV viral cytopathic effect (Figure 3). The second focus of myocarditis without these cytopathic effects was found within the cardiac conduction system including the atrioventricular node. Other findings at autopsy supported the diagnosis of SLE. Given the combination of autoimmune disease, immunosuppression and increased susceptibility to opportunistic infections, it was felt that the most likely cause of the patient's sudden cardiac death (SCD) was a combination of CMV myocarditis and complications of SLE.

\section{Discussion}

Acute myocarditis is generally considered to be a self-limited illness, typically associated with viral infection and a favorable outcome. In rare cases, however, it may lead to progressive heart failure and SCD. ${ }^{1}$ The definitive diagnosis of myocarditis is established via endomyocardial biopsy and testing for the

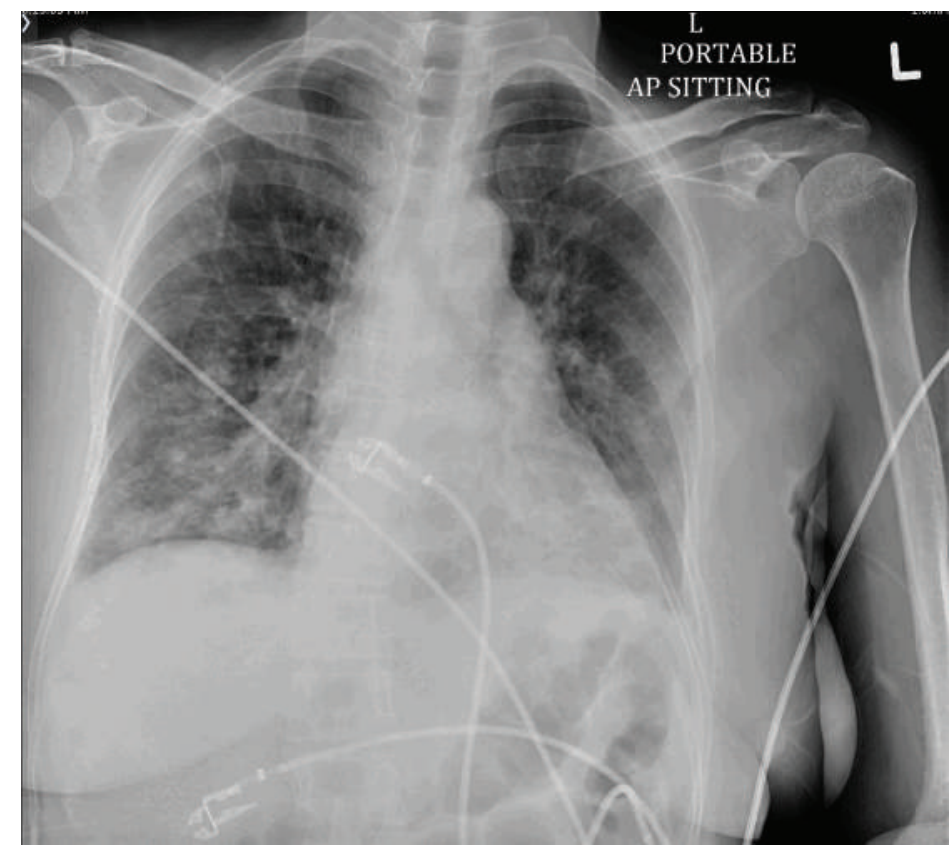

Figure 1. Initial anterior-posterior chest $\mathrm{x}$-ray in the emergency department demonstrating patchy opacities compatible with right lower lobe pneumonia.
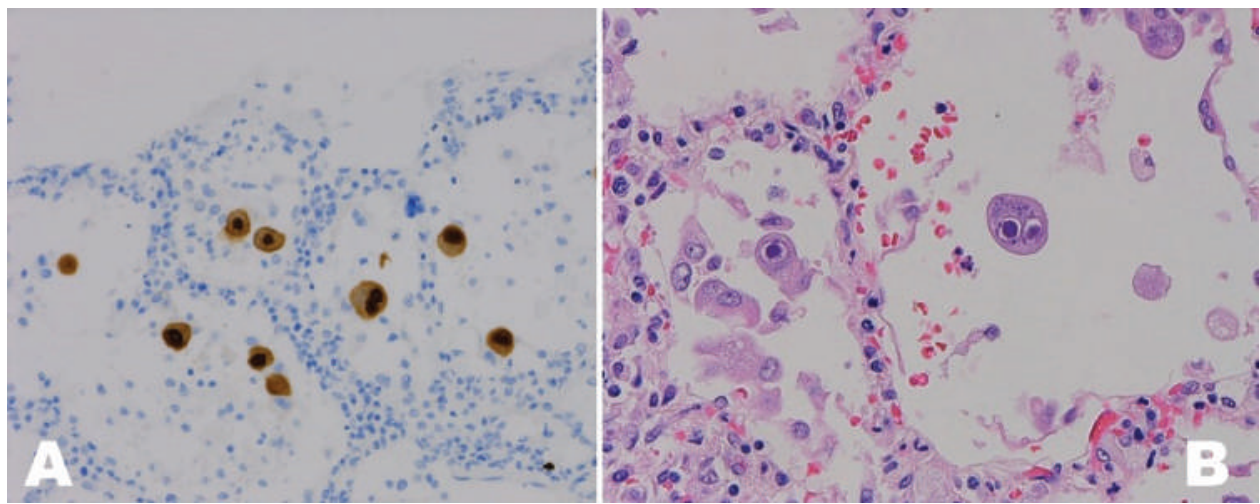

Figure 2. Cytomegalovirus pneumonitis. Immunohistochemistry (Panel A). Inclusion bodies on hematoxylin and eosin staining, identified with the arrow (Panel B). 


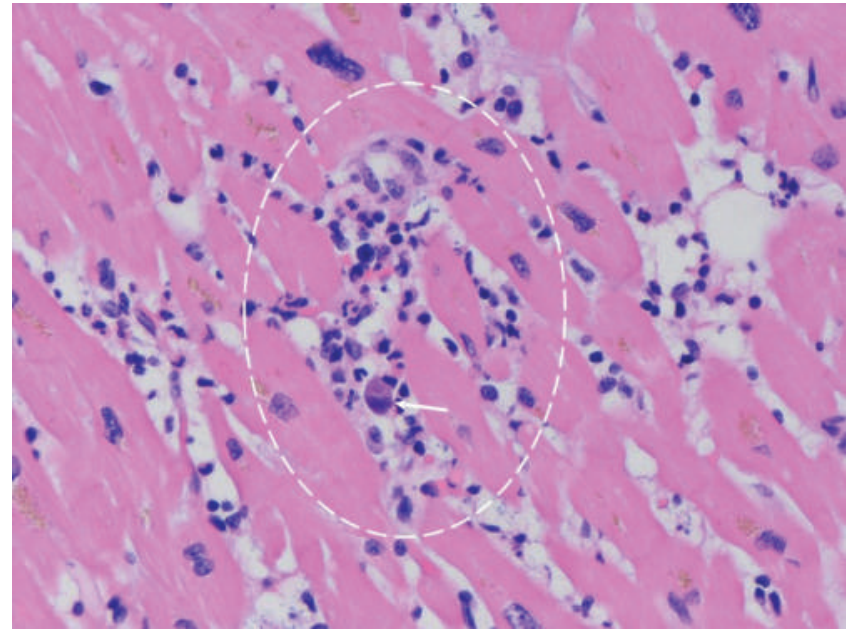

Figure 3. Left ventricular anterior wall myocardium (40× magnification): Focus of myocyte destruction and inflammatory infiltrate (white dashed circle) with single-cell demonstrating cytomegalovirus viral cytopathic effect (white arrowhead).

presence of a viral genome using molecular biologic techniques such as polymerase chain reaction (PCR). ${ }^{1}$ However, this is uncommon in practice as clinicians often infer the diagnosis based on clinical presentation and noninvasive tests such as cardiac magnetic resonance imaging (MRI) using established consensus criteria. ${ }^{2}$

Cytomegalovirus is a ubiquitous virus belonging to the Herpesviridae family. Transmission can occur via multiple routes, and like other members of this family, CMV establishes a latent infection after the resolution of an acute or primary infection. ${ }^{1,3}$ Reactivation can occur at any time; this risk is highest in the setting of systemic immunosuppression. ${ }^{4}$ Diagnosis of CMV infection requires evidence of viral replication in serum or whole blood via PCR while CMV disease requires evidence of endorgan dysfunction attributable to CMV infection. Typically, the treatment is with intravenous ganciclovir or oral valganciclovir. ${ }^{5}$ With respect to myocarditis, CMV is frequently found in more severe/fulminant cases in immunosuppressed individuals ${ }^{3,6}$ and has been associated with SCD; one study identified CMV as the causative pathogen of SCD in 38\% of autopsies in patients who had died of myocarditis. ${ }^{7}$

Connective tissue diseases like SLE can be associated with both infectious and autoimmune myocarditis, although the disease course and complications when these entities co-exist have not been well established. ${ }^{8,9}$ Also, autoimmune diseases are known to accelerate atherosclerotic heart disease, placing individuals at a higher risk of adverse cardiovascular events. ${ }^{10}$ In our case, the patient's autopsy findings of severe multi-vessel coronary artery disease at a relatively young age are in keeping with this. Although no evidence of ischemia or infarction was identified, an ischemic event could not be entirely ruled out as findings of infarction can take up to $12 \mathrm{~h}$ to manifest on light microscopy and the patient died shortly after her event. Nonetheless, the confirmed presence of myocarditis in the anterior wall of the left ventricle and cardiac conduction system was felt to make it a more likely cause of cardiac arrest.

To our knowledge, this is the first reported case of a patient with SCD in the context of autoimmune disease, pharmacologic immunosuppression, and subsequent diagnosis of CMV myocarditis involving the cardiac conduction system on autopsy. While the immediate cause of the patient's death remains undetermined, it is possible that immunosuppression with glucocorticoids and cyclophosphamide allowed for CMV reactivation and subsequent dissemination into the heart and lungs. Contributions from lupus myocarditis/pneumonitis and/or a primary CMV infection could not be ruled out. Unfortunately, SCD is a common presentation of this rare but important diagnosis; it is unknown whether earlier diagnosis/intervention would have changed our patient's outcome.

While it is impossible to identify causation, the autopsy findings make for a plausible mechanism of SCD that has not previously been reported. Myocarditis is a common clinical entity with variability in its presentation and severity, for which diagnosis using non-invasive measures can be difficult. Patients on immunosuppressive therapy such as SLE are at risk of opportunistic infections such as CMV and are thus prone to developing more severe forms of myocarditis and its complications during an acute flare. When caring for these patients, it is necessary for clinicians to be thorough in their diagnostic approach and to consider atypical manifestations of opportunistic pathogens, such as CMV, which would otherwise not be normally found in immunocompetent hosts.

\section{Consent for Publication Statement}

This case report describes a deceased patient. Exhaustive attempts to reach the patient's family members, both locally and internationally, to obtain consent for inclusion in a case report were unsuccessful. Accordingly, this work was subsequently reviewed by the Alberta Health Services Information and Privacy office. In accordance with standards set by the Committee on Publication Ethics (COPE), this work was deemed to have been sufficiently anonymized to make it suitable for publication in the scientific/medical literature as a case report after unsuccessful attempts to contact the patient's family. 


\section{References}

1. Feldman AM, McNamara D. Myocarditis [Internet]. New Engl J Med. 2000;343(19):1388-98. Available at: https://www.nejm.org/doi/full/10.1056/ NEJM200011093431908?url_ver=Z39.88-2003\&rfr_id=ori:rid:crossref. org\&rfr_dat=cr_pub\%3dpubmed

2. Friedrich MG, Sechtem U, Schulz-Menger J, Holmvang G, Alakija P, Cooper LT, et al. on behalf of the International consensus group on cardiovascular MR in myocarditis. Cardiovascular magnetic resonance in myocarditis: A JACC White Paper [Internet]. J Am Coll Cardiol. 2009;53(17):1475-87. Available from: http://www.onlinejacc.org/content/53/17/1475

3. Padala SK, Kumar A, Padala S. Fulminant cytomegalovirus myocarditis in an immunocompetent host: Resolution with oral valganciclovir [Internet]. Tex Heart Inst J. 2014;41(5):523-9. Available from: https://www.ncbi.nlm.nih .gov/pmc/articles/PMC4189357/

4. Sia IG, Patel R. New strategies for prevention and therapy of cytomegalovirus infection and disease in solid-organ transplant recipients [Internet]. Clin Microbiol Rev. 2000;13(1):83-121. Available from: https://www.ncbi.nlm.nih .gov/pmc/articles/PMC88935/

5. Kotton CN, Kumar D, Caliendo AM, Asberg A, Chou S, Danziger-Isakov $\mathrm{L}$, et al. Updated international consensus guidelines on the management of cytomegalovirus in solid-organ transplantation [Internet]. Transplantation. 2013;96:333-60. Available from: https://www.ncbi.nlm.nih.gov/ pubmed/23896556

6. Palmeira MM, Ribeiro HYU, Lira YG, Juca F, da Silva Rodrigues IA, da Paz LNF, et al. Heart failure due to cytomegalovirus myocarditis in immunocompetent young adults: A case report [Internet]. BMC Res Notes. 2016;9:31. Available from: https://www.ncbi.nlm.nih.gov/pmc/articles/ PMC4974773/

7. Kytö V, Vuorinen T, Saukko P, Lautenschlager I, Lignitz E, Saraste A, et al. Cytomegalovirus infection of the heart is common in patients with fatal myocarditis [Internet]. Clin Infect Dis. 2005;40(5):683-688. Available from: https://academic.oup.com/cid/article/40/5/683/364547

8. Ramos-Casals M, Cuadrado MJ, Alba P, Sanna G, Brito-Zerón P, Bertolaccini L, et al. Acute viral infections in patients with systemic lupus erythematosus: Description of 23 cases and review of the literature [Internet]. Medicine. 2008;87(6):311-8. Available from: https://insights.ovid.com/ pubmed?pmid=19011502

9. Tanwani J, Tselio K, Gladman DD, Su J, Urowitz MB. Lupus myocarditis: A single center experience and a comparative analysis of observational cohort studies [Internet]. Lupus. 2018;27:1296-302. Available from: https:// journals.sagepub.com/doi/abs/10.1177/0961203318770018?rfr_dat $=$ cr_ pub\%3Dpubmed\&url_ver=Z39.88-2003\&rfr_id=ori\%3Arid\%3Acrossref. org\&journalCode=lupa

10. Alenghat FJ. The prevalence of atherosclerosis in those with inflammatory connective tissue disease by race, age and traditional risk factors [Internet]. Sci Rep. 2016;6:20303. Available from: https://www.ncbi.nlm.nih.gov/ pubmed/26842423 